\title{
Dicle Nehri'nin belirli lokalitelerinde sedimentte ölçülen bazı ağır metallerin mevsimsel değişimi
}

\author{
Çiğdem KAYMAK ABAY * \\ Dicle Üniversitesi Fen Bilimleri Enstitüsü Biyoloji Bölümü, Diyarbakır. \\ Geliş Tarihi (Recived Date): 10.03.2017 \\ Kabul Tarihi (Accepted Date): 17.08.2017
}

\section{Özet}

Bu çalışmada, Eylül 2013- Eylül 2014 tarihleri arasında Dicle Nehri'nde belirlenen üç lokaliteden alınan sediment örneklerinde $\mathrm{Cu}, \mathrm{Ni}, \mathrm{Co}, \mathrm{Zn}, \mathrm{Cd}$ ve $\mathrm{Pb}$ konsantrasyonlarının belirlenmesi amaçlanmıştır. Örneklerin analizleri ICP-OES cihazı ile yapılmıştır. Sedimentlerde yapılan ă̆ır metal analizlerinde $\mathrm{Cu}, \mathrm{Ni}, \mathrm{Co}, \mathrm{Zn}$ ve $\mathrm{Pb}$ üç lokalitede de her mevsim ölçülürken, Cd metali ise çallşma süresince ICP-OES cihazının analiz limitinin altında kaldığı için tespit edilememiştir. I. lokalitede analiz edilen tüm metaller sonbaharda; II. lokalitede Zn yaz, diğer metaller sonbaharda; III. lokalitede $\mathrm{Zn}$ ve $\mathrm{Pb}$ ilkbaharda, $\mathrm{Cu}$, Ni ve Co ise sonbaharda en yüksek değerlerde ölçülmüşü̈r. Sonuç olarak, sedimentte limit değer olarak kabul edilen PECs (Probable Effects Concentration) verilerine göre sadece Ni metali tüm lokalitelerde yüksek bulunmuştur.

Anahtar kelimeler: Dicle Nehri, sediment, ăgır metal, ICP-OES.

\section{The seasonal variations of some heavy metals measured in sediment at specific lokalities of Tigris River}

\begin{abstract}
In this study, it was aimed to determine $\mathrm{Cu}, \mathrm{Ni}, \mathrm{Co}, \mathrm{Zn}, \mathrm{Cd}$ and $\mathrm{Pb}$ concentrations in sediment which was taken from between September 2013 and September 2014 at three localities of Tigris River. Analysis of the samples was carried out by ICP-OES device. $\mathrm{Cu}, \mathrm{Ni}, \mathrm{Co}, \mathrm{Zn}$ and $\mathrm{Pb}$ were measured at all seasons of three locality in heavy metal analyzes in sediments, while Cd metal was not detected because it was below the limit of analysis of ICP-OES during the study period. The highest values were measured in I. locality all metals in the fall; II. locality Zn summer, other metals in the fall; III. locality
\end{abstract}

\footnotetext{
*Çiğdem KAYMAK ABAY, kaymakcigdem@gmail.com, http://orcid.org/0000-0002-4827-8488
} 
$\mathrm{Zn}$ and $\mathrm{Pb}$ in the spring, $\mathrm{Cu}, \mathrm{Ni}$ and Co metals in autumn. As a result, according to the PECs (Probable Effects Concentration), which is accepted as the limit value of sediment, only Ni metal is found higher in all localities.

Keywords: Tigris River, sediment, heavy metal, ICP-OES.

\section{Giriş}

Yeryüzünde karasal ve sucul canlılar için kullanılabilir tatlı su kaynakları toplam suyun çok az bir kısmını oluşturmaktadır. Bu kaynaklarda artan nüfus yoğunluğu ve teknoloji ile beraber her geçen gün çeşitli sebeplerle kirliliğe maruz kalmaktadır. Kirliliğe neden olan kaynakların başında antropojenik ve endüstriyel sebeplerle su sistemine karışan ağır metaller gelmektedir. Metaller ortamda uzun süre kalabilmeleri ve fiziksel yöntemlerle ayrışamamalarından dolayı çevre için en tehlikeli kirleticiler grubuna girmektedir [1, 2].

Ağır metaller sucul ekosistemlerde sedimentte birikerek tüm su canlılarını etkilemektedirler. Suya karışan çözünür durumdaki metaller dibe çökerek sediment ile birleşirler. Bu nedenle sucul sistemlerde sedimentler metallerin depolandığ bilinmektedir [3,4]. Sedimentte biriken bu metaller bentik organizmalara oradan da besin zinciri yoluyla diğer canlılara geçebilmektedir.

Ülkemizde farklı tatlı su sistemlerinde sedimentteki ağır metal birikimlerinin araştırılmasına yönelik çeşitli çalışmalar mevcuttur [5-12].

$\mathrm{Bu}$ çalışmada Dicle Nehri üzerinde belirlenen üç lokaliteden alınan sediment örneklerinde $\mathrm{Cu}, \mathrm{Ni}, \mathrm{Co}, \mathrm{Zn}, \mathrm{Cd}$ ve $\mathrm{Pb}$ gibi ağır metallerin birikim düzeylerinin mevsimlere göre nasıl değiştiği tespit edilmeye çalışılmıştır. Böylece kirliliğin ulaştığı boyutlar hakkında bilgi sahibi olmak amaçlanmıştır.

\section{Materyal ve metot}

Dicle nehri ve kolları önemli birer su gücü kaynağı ve sulama değeri taşıyan akarsulardır. Bu çalışma Eylül 2013- Eylül 2014 tarihleri arasında Dicle Nehri üzerinde seçilen üç lokalite üzerinde gerçekleştirilmiştir. Çalışma alanının haritası Şekil 1'de, lokalitelerin koordinat bilgisi ise Tablo 1'de verilmiştir.

Tablo 1. Lokalitelere ait koordinatlar

\begin{tabular}{|l|ll|}
\hline Lokaliteler & Koordinatlar \\
\hline Diyarbakir (I. Lokalite) & $37^{\circ} 36^{\prime} 35.298^{\prime \prime} \mathrm{K}$ & $41^{\circ} 58^{\prime} 33.06 " \mathrm{D}$ \\
\hline Bismil (II. Lokalite) & $37^{\circ} 38^{\prime} 45.5814^{\prime \prime} \mathrm{K}$ & $41^{\circ} 53^{\prime} 41.496 " \mathrm{D}$ \\
\hline Hasankeyf (III. Lokalite) & $37^{\circ} 42^{\prime} 45.0786^{\prime \prime} \mathrm{K}$ & $4^{\circ} 46^{\prime} 11.244 " \mathrm{D}$ \\
\hline
\end{tabular}




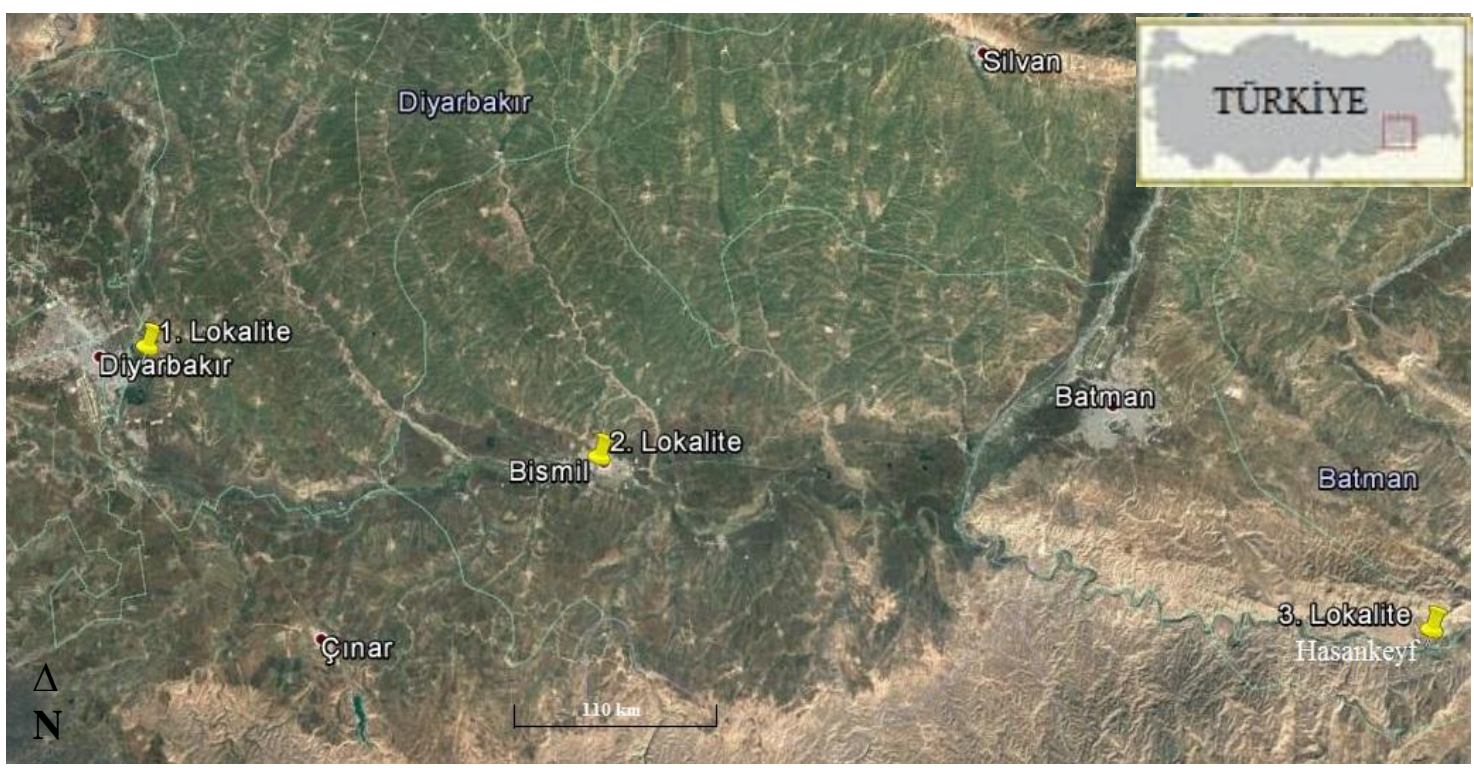

Şekil 1. Dicle Nehri üzerinde örnekleme yapılan lokaliteler

Sediment örnekleri belirlenen lokalitelerden ve nehrin dip kısımlarından bir kürek yardımıyla 3 'er adet alınarak üzerine alındığ 1 istasyonun adı, tarihi ve saatini içeren etiket yapıştırılarak torbalara bırakılmış ve laboratuara getirilmiştir. Laboratuara getirilen sediment örnekleri ilk aşamada iyice karıştırılarak homojen hale getirilmiştir. Daha sonra saat camlarına aktarılarak etüvde $110^{\circ} \mathrm{C}$ de 72 saat tutularak sabit kuru ağırlığa getirilmiştir. Kurutulmuş örnekler porselen havanda iyice dövülerek homojen hale getirilmiştir. Homojen hale getirilen sediment örnekleri 100 mesh'lik elekten geçirilerek polietilenli kaplara alınıp tekrar etüve konulup 1-2 saat bekletilmiştir. Etüvden alındıktan sonra etiketleme işlemleri yapılarak analiz yapılıncaya kadar nem kapmalarını engellemek amacıyla desikatörde bekletilmiştir. Ayrıca kullanılan tüm malzemeler (saat camı, baget, havan, polietilen kaplar) bir sonraki kullanım için temizlenip hazır hale getirilmiştir. Desikatörde bekletilen numuneler $0.001 \mathrm{~g}$ hassasiyetli dijital elektronik terazi ile tartılarak her bir sediment numunesinden $0.1 \mathrm{~g}$ alınmış ve mikrodalga çözünürleştirme tüplerine aktarılmıştır. Sediment örneklerinin üzerine $3 \mathrm{ml} \mathrm{HNO}_{3}, 9 \mathrm{ml} \mathrm{HCl}$ ve $2 \mathrm{ml} \mathrm{HF}$ çözeltisi ilave edilmiştir. İçinde numunelerin bulunduğu 12 adet tüp mikrodalga fırınına yerleştirilerek çözünürleştirme işlemi başlatılmıştır.

Mikrodalga firınında 40 dakikalık çözünürleştirme işlemi yapıldıktan sonra firından çıkarılan tüplerin oda sıcaklığında soğumaları sağlanmıştır. Soğuyan tüplerin kapakları çeker ocakta açılmış ve asit çıkışı için bir süre beklenmiştir. Asit çıkışı bittikten sonra çözünen numuneler kantitatif filtre kağıtları $(\varnothing 11 \mathrm{~cm})$ yerleştirilerek hazırlanmış cam huniler yardımıyla süzülerek 15 ml'lik falkon tüplerine aktarılmıştır. Ultra saf su ile miktarları 15 ml'ye tamamlanmıştır. Sediment örneklerindeki Cu, Ni, Co, $\mathrm{Zn}, \mathrm{Cd}$ ve $\mathrm{Pb}$ gibi ağır metallerin miktarları Perkin Elmer Optima 2100 DV markalı ICP-OES cihazı ile ölçülmüştür. Analizi yapılacak $\mathrm{Cu}, \mathrm{Ni}, \mathrm{Co}, \mathrm{Cd}, \mathrm{Pb}$ ağır metalleri için 0.025, 0.05, $0.1,0.3,0.5,1,1.5 \mathrm{ppm}$ konsantrasyonlarda, Zn metali için $0.5,1,1.5,2,2.5$ ppm standartlarda çözeltiler hazırlanmıştır. Analiz esnasında olabilecek hata payını en aza indirebilmek için örneklerdeki asit miktarı ile orantılı olarak hazırlanan standartlara \% 2'lik $\mathrm{HNO}_{3}$ ilave edilmiştir. Sonuçlar kuru ağırlık üzerinden $\mathrm{mg} / \mathrm{kg}$ olarak verilmiştir. 
Lokalite sedimentlerinde yapılan çözünürleştirme ve analiz sonuçlarının doğruluğundan emin olabilmek için standart referans materyal olarak Sediment- LGC6189 standart referans materyal kullanılmış ve sonuçlar Tablo 2'de verilmiştir.

Lokalitelerde sedimentte mevsimsel olarak ölçülen ağır metal konsantrasyonlarının istatistiksel hesaplamaları SPSS 16.0 programı kullanılarak One-Way Anova'nın posthoc testlerinden Tukey ile yapılmıştır. Grafikler ise Microsoft Excel programı ile oluşturulmuştur.

\section{Bulgular}

Sediment ve referans materyal ile ICP-OES cihazı ile yapılan ölçümler 3'er tekrarlı olarak gerçekleştirilmiştir. Referans materyal ile ölçülen değerlerde en düşük uyumluluk \% 96 ile $\mathrm{Pb}$ 'da, en yüksek uyumluluk ise \% 109 ile $\mathrm{Cu}$ metalinde ölçülmüştür.

Tablo 2. LGC6189 Nehir Sediment referans materyal ile ölçülen değerler

\begin{tabular}{|c|c|c|c|}
\hline Metaller & $\begin{array}{c}\text { Referans Değerler } \\
(\mathbf{m g} / \mathbf{k g})\end{array}$ & $\begin{array}{c}\text { Ölçülen Değerler } \\
(\mathbf{m g} / \mathbf{k g})\end{array}$ & $\begin{array}{c}\text { Uyumluluk } \\
(\mathbf{\%})\end{array}$ \\
\hline $\mathrm{Cu}$ & $87 \pm 8$ & $95.66 \pm 6.76$ & 109 \\
\hline $\mathrm{Ni}$ & $34 \pm 3$ & $36.79 \pm 2.64$ & 108 \\
\hline $\mathrm{Zn}$ & $460 \pm 30$ & $480.7 \pm 6.12$ & 104 \\
\hline $\mathrm{Pb}$ & $87 \pm 6$ & $83.91 \pm 0.36$ & 96 \\
\hline
\end{tabular}

Lokalitelerden elde edilen sediment örneklerindeki ağır metal konsantrasyonları mevsimsel olarak karşılaştırılmıştır. Bu lokalitelerdeki ağır metal konsantrasyonlarının ortalama değer, istatistiksel farklılıkları ile mevsimsel değişimleri Tablo 3 'te verilmiştir.

I. lokalitede yapılan $\mathrm{Cu}$ sonbahar-2013 > yaz > ilkbahar > sonbahar-2014, Ni sonbahar2013 > ilkbahar > yaz > sonbahar-2014, Co sonbahar-2013 > yaz > ilkbahar > sonbahar-2014, Zn sonbahar-2013 > yaz > sonbahar-2014 > ilkbahar, Pb sonbahar2013 > ilkbahar > yaz > sonbahar-2014 olarak belirlenmiştir. Tüm metallerde ortalama konsantrasyon değerlerinin sonbahar-2013'te yüksek olduğu görülmüsşür. En düşük metal konsantrasyonu ise $\mathrm{Cu}, \mathrm{Ni}$, $\mathrm{Co}$ ve $\mathrm{Pb}$ da sonbahar-2014; $\mathrm{Zn}$ da ilkbahar mevsiminde ölçülmüştür (Şekil 2). I. lokalite sedimentinde $\mathrm{Cu}, \mathrm{Ni}, \mathrm{Co}, \mathrm{Zn}$ metallerinde mevsimler arasında anlamlı bir farklılık olmadığ $(\mathrm{p}>0.05)$; $\mathrm{Pb}$ metalinde sonbahar2013'ün diğer üç mevsimden, sonbahar-2014'ün de ayrıca ilkbahardan anlamlı bir şekilde farklı olduğu görülmüştür $(\mathrm{p}<0.05)$.

II. lokalitede $\mathrm{Cu}, \mathrm{Ni}, \mathrm{Pb}$ konsantrasyonları sonbahar-2013 > ilkbahar > sonbahar-2014 $>$ yaz, Co sonbahar-2013 > sonbahar-2014 > ilkbahar > yaz, Zn yaz > sonbahar-2013 > sonbahar-2014 > ilkbahar olarak belirlenmiştir. $\mathrm{Cu}, \mathrm{Ni}, \mathrm{Co}$ ve Pb'un ortalama konsantrasyon değerlerinin sonbahar-2013, Zn'nun yaz aylarında en yüksek düzeyde olduğu, en düşük metal birikiminin ise $\mathrm{Cu}, \mathrm{Ni}, \mathrm{Co}$ ve $\mathrm{Pb}$ için yaz, $\mathrm{Zn}$ için ilkbahar mevsimi olduğu gözlenmiştir (Şekil 2). II. lokalite sedimentindeki $\mathrm{Cu}$, $\mathrm{Ni}$ ve $\mathrm{Zn}$ konsantrasyonlarının istatistiksel olarak farklılık göstermediği $(\mathrm{p}>0.05) ; \mathrm{Co} \mathrm{ve} \mathrm{Pb}$ konsantrasyonunda sonbahar-2013'ün yaz mevsiminden istatistiksel olarak önemli bir farka sahip olduğu saptanmıştır $(\mathrm{p}<0.05)$. 
III. lokalitede $\mathrm{Cu}$ ve Ni sonbahar-2014 > yaz > sonbahar-2013 > ilkbahar, Co sonbahar$2014>$ sonbahar-2013 > yaz > ilkbahar, Zn ilkbahar > sonbahar-2013 > sonbahar-2014 $>$ yaz, $\mathrm{Pb}$ ilkbahar > yaz > sonbahar-2013 > sonbahar-2014 olarak belirlenmiştir. $\mathrm{Cu}$, $\mathrm{Ni}$ ve Co ta en yüksek konsantrasyon sonbahar-2014'te, $\mathrm{Zn}$ ve $\mathrm{Pb}$ da ise en yüksek konsantrasyon değeri ilkbahar mevsiminde görülmüsstür. En düşük metal birikiminin ise $\mathrm{Cu}$, Ni ve Co için ilkbahar; $\mathrm{Zn}$ için yaz; $\mathrm{Pb}$ için sonbahar-2014 olduğu tespit edilmiştir (Şekil 2). Ni, $\mathrm{Zn}$ ve $\mathrm{Pb}$ konsantrasyonlarının mevsimler arasındaki farkı istatistiksel olarak önemli bulunmamıştır $(\mathrm{p}>0.05)$. $\mathrm{Cu}$ konsantrasyonunda sonbahar-2014'ün ilkbahar-2014 ve sonbahar-2013 ten; Co konsantrasyonunda sonbahar-2014'ün ilkbahar ve yaz mevsiminden istatistiksel olarak anlamlı bir farka sahip olduğu bulunmuştur $(\mathrm{p}<0.05)$.

Aynı lokalitenin mevsimleri arasındaki etkileşim incelendiğinde I. lokalitede $\mathrm{Pb}$ ( $\mathrm{F}=45.371 ; \mathrm{P}=0.000)$; II. lokalitede $\mathrm{Co}(\mathrm{F}=4.597 ; \mathrm{P}=0.038), \mathrm{Pb}(\mathrm{F}=5.506 ; \mathrm{P}=0.024) ;$ III. lokalitede $\mathrm{Cu}(\mathrm{F}=9.561 ; \mathrm{P}=0.005)$, $\mathrm{Co}(\mathrm{F}=5.649 ; \mathrm{P}=0.022)$ konsantrasyonlarının anlamlı olduğu tespit edilmiştir $(\mathrm{p}<0.05)$. 
Tablo 3. Dicle Nehri sedimentlerinde ölçülen ortalama ağır metal konsantrasyon değerlerinin mevsimlere göre değişimi (mg/kg kuru ağırlık) (Ortalama değer \pm Standart sapma, Minimum-Maksimum değerler parantez içinde verilmiştir)

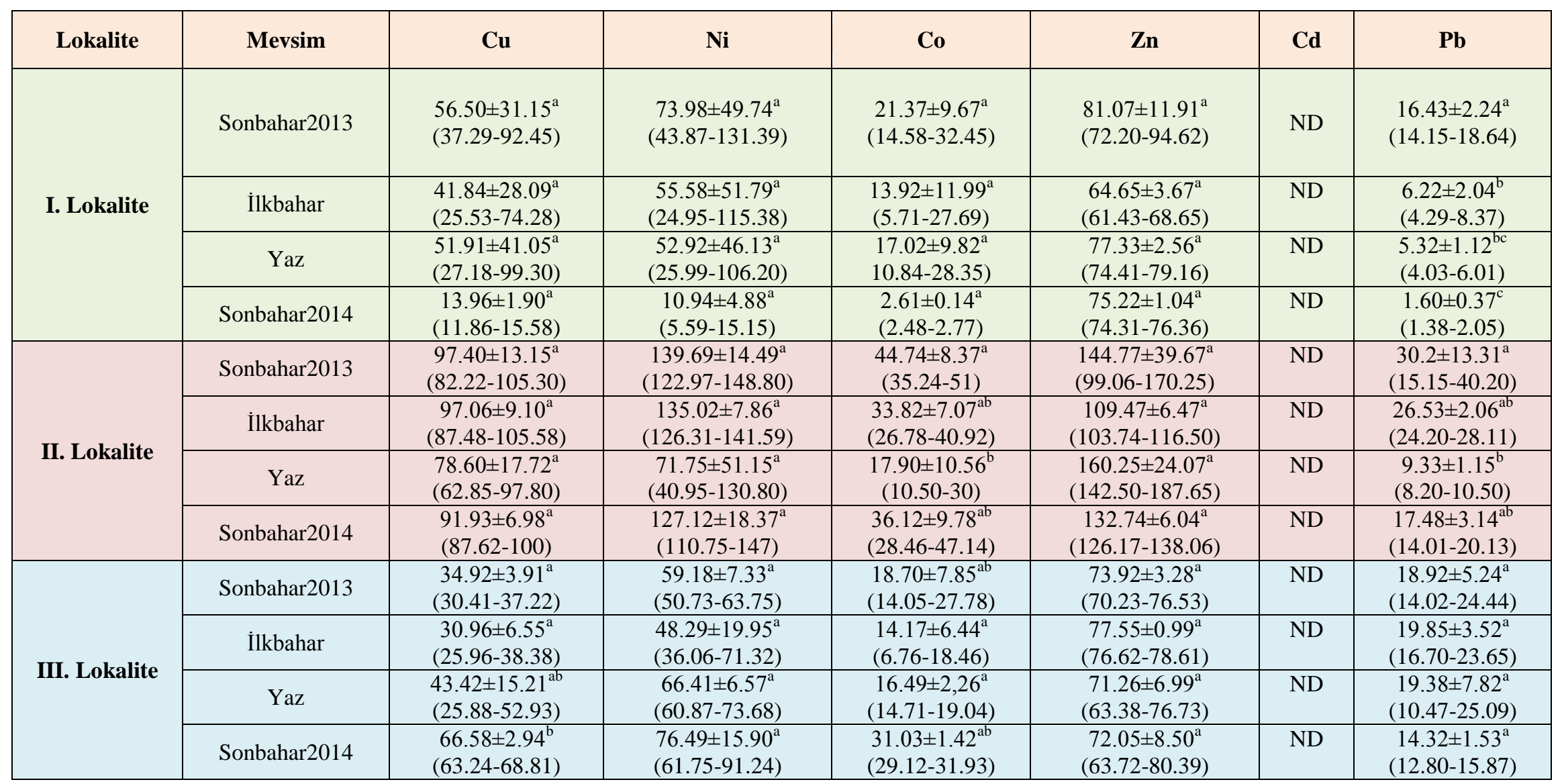

Aynı sütundaki farklı harfler lokalitelerde mevsimler arasında farkın istatistiksel olarak önemli olduğunu ifade etmektedir ( $<<0.05$ ). a, b, c harfleri lokalite mevsimleri arasındaki farklılığı gösterir. ND: Ölçümler ICP-OES'in analiz limitinin altındadır. Cd için bu değer 0.012 mg/L olarak ölçülmüştür. 

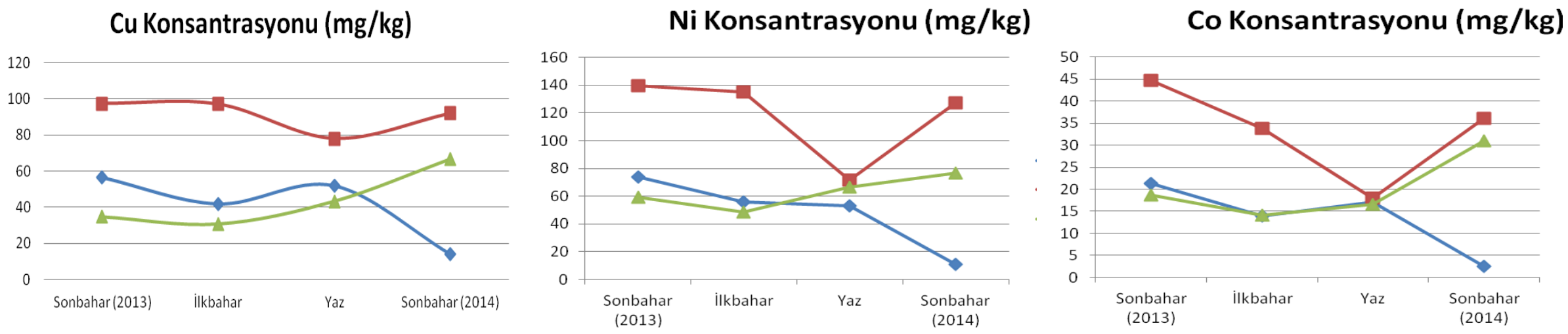

Zn Konsantrasyonu (mg/kg)

Pb Konsantrasyonu (mg/kg)
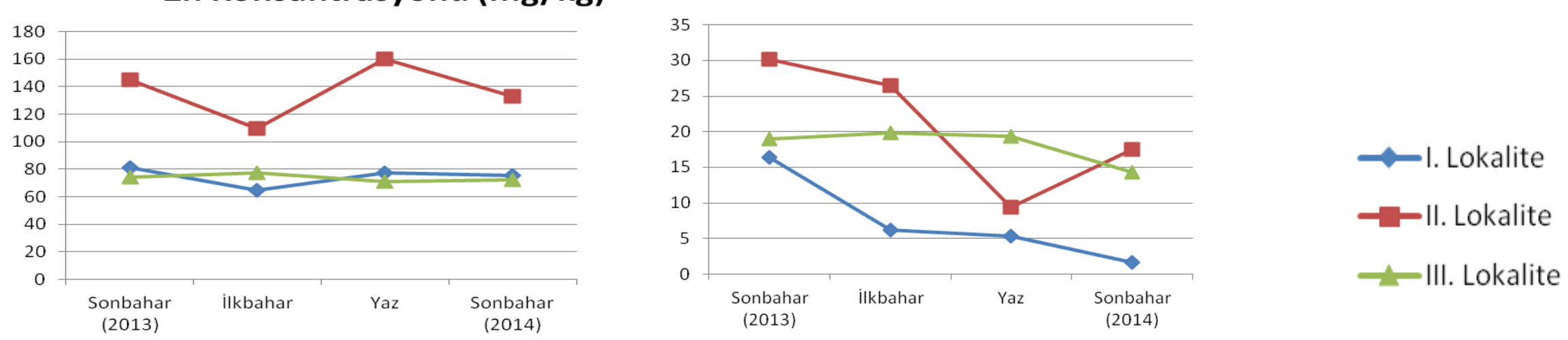

Şekil 2. Dicle Nehri'nde belirlenen lokalitelerin sedimentlerinde mevsimsel olarak ölçülen ağır metal konsantrasyonlarının değişim grafikleri 


\section{Sonuçlar ve tartışma}

Eylül 2013- Eylül 2014 tarihleri arasında yapılan çalışmada sedimentte ağır metal konsantrasyonu üç lokalitede de sırasıyla $\mathrm{Zn}>\mathrm{Ni}>\mathrm{Cu}>\mathrm{Co}>\mathrm{Pb}$ olarak belirlenmiștir. Mevsimsel olarak ortalama değerler dikkate alınarak yapılan karşılaştırmada metallerin sonbahar ve ilkbahar mevsimlerinde daha yüksek düzeyde oldukları belirlenmiştir. Benzer sonuç Kaçar [14] tarafından da kaydedilmiştir. Bu durum yağışlı mevsimlerde sedimentteki metal konsantrasyonun artması yağmur sularıyla nehre taşınan toprakta bulunan metallerden kaynaklı olabilir [13].

Bulgularımızın Al-Ani ve ark.'nın [15], Bağdat'ta Dicle Nehri sedimentinde yapmış oldukları ağır metal sonuçları ile karşılaştırıldığında, Zn metalini 70-480 ppm konsantrasyon aralığında, Co metalini 40-148 ppm konsantrasyon aralığında çalışmamıza göre daha yüksek, $\mathrm{Cu}$ metalini 40-110 ppm konsantrasyon aralığında çalışmamıza paralel olarak bulmuşlardır. Balasim ve ark.'nın [16] Dicle Nehri'nin Bağdat Bölgesi'nde yaptıkları çalışmada sedimentte Zn metalinin en yüksek değerini kış mevsiminde 188 ppm olarak 4. istasyonda, en düşük konsantrasyonu yaz mevsiminde 1. istasyonda $51.2 \mathrm{ppm}$ olarak ölçmüşlerdir. Cd metalinde en düşük konsantrasyonu (0.5 ppm) Aralık ve Şubat ayında, en yüksek konsantrasyonu (2.5 ppm) Ekim ayında ölçmüşlerdir. Çalışmamızda $\mathrm{Cd}$ değeri ICP-OES cihazının analiz limitinin altında olduğu için tespit edilememiştir. Varol ve Şen [17] Dicle Nehri'nde yaptıkları çalışmada sedimentte ağır metal konsantrasyonunu $\mathrm{Fe}>\mathrm{Cu}>\mathrm{Mn}>\mathrm{Zn}>\mathrm{Pb}>\mathrm{Ni}>\mathrm{Co}>\mathrm{Cr}>\mathrm{As}>\mathrm{Cd}$ şeklinde bulmuşlardır. Karadede-Akın ve Ünlü [18], Dicle Nehri sedimentinde yapmış oldukları çalışmada konsantrasyonları $\mathrm{Fe}>\mathrm{Mn}>\mathrm{Cu}>\mathrm{Co}>\mathrm{Zn}$ olarak belirlemişlerdir. Gümgüm ve ark. [19] tarafından, Dicle Nehri sedimentinde yapılan çalışmada ağır metal sonuçlarının en yüksek değerlerinin Co: 503, Cu: 3433, Ni: 403, Zn: 489, Pb: 102 ppm olarak bildirmiş̧lerdir. Ergani Bakır Fabrikası atıklarının Dicle Nehri'ne boşaltılmasından dolayı nehrin kirlenmiş olduğunu ifade etmişlerdir. Gümgüm ve Öztürk [20] Dicle Nehri'nde yapmış oldukları çalışmada ise bu değerlerde (Co: 32.01, $\mathrm{Cu}:$ 728.96, Ni: 66.35, Zn: 369.14 ppm) önemli bir düşüş olduğunu görmüşlerdir. Bunun nedenini ise Ergani Bakır Fabrikasının özelleştirilmesi ile birlikte üretim kapasitesinin azaltılması ve arıtma tesisi kurması sayesinde olduğunu belirtmişlerdir. Yaptığımız çalışma ile karşılaştırıldığında, Dicle Nehri'nin 1994-2001 yıllarına göre çok daha düşük oranda $\mathrm{Cu}, \mathrm{Zn}$ ve $\mathrm{Pb}$ içerdiği tespit edilmiştir. Al-Ani ve ark. Dicle Nehri'nin ağır metal kirlilik kaynaklarını bölgenin jeomorfolojik yapısı, sedimentteki organik madde miktarı, kimyasal ve biyolojik faktörler ile suyun $\mathrm{pH}$ değerlerinin etkileyebileceğini belirtmişlerdir [15].

Farklı çalışmalarda sedimentte metal konsantrasyonlarının farklı olması yağışlar, sıcaklık, akarsuyun debisi, sediment miktarı ve yapısı ile birlikte dönemsel ve bölgesel değişiklik gösteren antropojenik ve endüstriyel atıklar, tarımsal faaliyetler ile yakından ilgilidir [21,22].

Sonuç olarak Dicle Nehri sedimentinde yapılan ağır metal konsantrasyonları Macdonald ve ark.'nın [23] ortaya koymuş olduğu PECs (Probable Effects Concentrations) değerleri (Cu: 150, Ni: 49, Zn: 460, Cd: 5, Pb: $130 \mathrm{mg} / \mathrm{kg}$ ) ile karşılaştırıldığında sadece Ni metali tüm lokalitelerde yüksek bulunmuştur. Dicle nehir sisteminin geleceği açısından önemli olan bu tarz çalışmalar düzenli aralıklarla yapılmalıdır. 


\section{Teșekkür}

$\mathrm{Bu}$ çalışma doktora tezinden üretilmiştir. 12-FF-85 No'lu Proje ile çalışmayı maddi olarak destekleyen Dicle Üniversitesi Bilimsel Araştırma Projeleri Yönetim Birimi Başkanlığı'na teşekkür ederim.

\section{Kaynaklar}

[1] Bryan, G. W., Effects of pollutants on aquatic organisms in Lockwood, A. P. M., Some aspects of heavy metal tolerance in aquatic organisms, 7-44, Cambridge University Press, (1976).

[2] Kasassi, A., Rakimbei, P., Karagiannidis, A., Zabaniotou, A., Tsiouvaras, K., Nastis, A., Soil contamination by heavy metals: Measurements from a closed unlined landfill, Bioresource Technology, 99, 8578-8584, (2008).

[3] Goyer, R,A., The Basic Science of Poisons in Amdur, M.O., Doull, J., Klaassen, C.D. (eds.), Toxic Effects of Metals, Pergamon Press, London, UK, 623-680, (1986).

[4] Salomans, W., Rooij, N. M., Kerdijk, H. ve Bril, J., Sediments as a Source for Contaminants, Hydrobiologia, 149, 13-30, (1987).

[5] Kır, İ., Tekin-Özan, S., Tuncay, Y., Kovada Gölü'nün su ve sedimentindeki bazı ağır metallerin mevsimsel değişimi. Ege Journal of Fisheries and Aquatic Sciences, 24, 1-2, 155-158, (2007).

[6] Kiracı, A., Azap Gölü'nün sedimentlerindeki ve sularındaki ağır metal miktarlarının belirlenmesi, Yüksek Lisans Tezi, Adnan Menderes Üniversitesi, Fen Bilimleri Enstitüsü, Aydın, (2014).

[7] Türkmen, A., Aras, S., İskenderun Körfezi'nde deniz suyu ve sedimentte oluşan ağır metal birikiminin incelenmesi, Karadeniz Fen Bilimleri Dergisi, 1, 3, 123, (2011).

[8] Kükrer, S., Erginal, A. E., Şeker, S., Karabıyıkoğlu, M., Distribution and environmental risk evaluation of heavy metal in core sediments from Lake Çıldır (NE Turkey), Environmental Monitoring and Assessment, 187, 453-467, (2015).

[9] Tunca-Üçüncü, E., Beyşehir Gölü'nde su ve sedimentte ağır metal birikimi ve sedimentte antropojenik kontaminasyon değerlendirmesi, Ordu Üniversitesi Bilim Teknik Dergisi, 6, 2, 205-219, (2016).

[10] Erol, S., Cukrov, N., Franc 'iškovic'-Bilinski, S., Kurt, M.A., Mihri, H.,Contamination assessment of ecotoxic metals in recent sediments from the Ergene River, Turkey, Environmental Earth Science, 75, 1051-1062, (2016).

[11] Ünlü, S., Alpar, B., An assessment of trace element contamination in the reshwater sediments of Lake İznik (NW Turkey), Environmental Earth Science, 75, 140-154, (2016).

[12] Kalyoncu, H., Özan, C. , Tekin-Özan, S., Isparta Deresi'nin su ve sedimentlerindeki ağır metal birikiminin incelenmesi, Mehmet Akif Ersoy Üniversitesi Fen Bilimleri Enstitüsü Dergisi, 7, (Ek Sayı 1), 268-280, (2016).

[13] Yüzereroğlu, T.A., Gök, G., Fira, O., Aslanyavrusu, S., Maruldali, O., Kargin, F., Heavy metals in Patella caerulea (Mollusca, Gastropoda) in polluted and nonpolluted areas from the Iskenderun Gulf (Mediterranean Turkey), Environmental Monitoring and Assessment, 167, 257-264, (2010). 
[14] Kaçar, E., Dicle Nehri’nin Ilısu Baraj Göl Bölgesi'ndeki su, sediment ve bazı balıklardaki ağır metal birikiminin incelenmesi, Yayımlanmamış Doktora Tezi, Dicle Üniversitesi, Fen Bilimleri Enstitüsü, Diyarbakır, (2015).

[15] Al-Ani, T., Al-Ansari, N., Dawood, A. H., Siergieiev, D., Knutsson, S., Trace metals in water and sediments of the Tigris River, Baghdad city, Iraq, Journal of Environmental Hydrology, 22, 6, 1-17, (2014).

[16] Balasim, H. M., Al-Azzawi, M. N., Rabee, A. M., Assessment of pollution with some heavy metals in water, sediments and Barbus xanthopterus fish of the Tigris River-Iraq, Iraqi Journal of Science, 54, 4, 813-822, (2013).

[17] Varol , M., Şen, B., Assessment of nutrient and heavy metal contamination in surface water and sediments of the upper Tigris River, Turkey, Elsevier, 92, 110, (2012).

[18] Karadede, H., Ünlü, E., Heavy metal concentrations in water, sediment, fish and some benthic organisms from Tigris River, Turkey, Environmental Monitoring and Assessment, 131, 323-337, (2007).

[19] Gümgüm, B., Ünlü, E., Tez, Z., Gülsün, Z., Heavy metal pollution in water, sediment and fish from the Tigris River in Turkey, Chemosphere, 29, 1, 111116, (1994).

[20] Gümgüm, B., Öztürk, G., Chemical speciation of heavy metals in the Tigris River sediment, Chemical Speciation \& Bioavailability, 13, 1, 25-29, (2001).

[21] Begüm, A., Ramaiah, M., Harikrishna, K. İ., Veena, K., Heavy metal pollution and chemical profile of Cauvery River Water, Journal of Chemistry, 6, 1, 4752, (2009).

[22] Öner, O., Çelik, A., Gediz Nehri Aşağı Gediz Havzası'ndan alınan su ve sediment örneklerinde bazı kirlilik parametrelerinin incelenmesi, Ekoloji, 20, 78, 48-52, (2011).

[23] MacDonald, D.D., Ingersoll, C.G., Berger, T.A., Development and evaluation of consensus-based sediment quality guidelines for freshwater ecosystems, Archives of Environmental Contamination and Toxicology, 39, 20-31, (2000). 